\title{
RHEOLOGICAL AND THERMAL CHARACTERISTICS OF WHEAT GLUTEN BIOPOLYMERS PLASTICIZED WITH GLYCEROL
}

\author{
Shana Pires Ferreira* e Walter Augusto Ruiz \\ Escola de Química e Alimentos, Universidade Federal do Rio Grande, CP 474, 96200-970 Rio Grande - RS, Brasil \\ António Gaspar-Cunha \\ Departamento de Engenharia de Polímeros, Universidade do Minho, Campus de Azurém, 4800-058 Guimarães, Portugal
}

Recebido em 18/5/11; aceito em 27/10/11; publicado na web em 13/1/12

\begin{abstract}
The objective this work was to obtain bioplastics from mixtures of wheat gluten and glycerol by two different processes and evaluate their respective rheological properties. The mixtures and their respective bioplastics were obtained through direct batch mixing under approximately adiabatic and isothermal conditions. The bioplastics showed high values for the storage $\left(G^{\prime}\right)$ and loss $\left(G^{\prime \prime}\right)$ moduli, suggesting a stronger protein network formed in both processes. The temperature onset and the percentage of weight loss to be estimated were found to be near in both bioplastics. The bioplastics have demonstrated to be materials of interesting potential of use as biodegradable barrier materials.
\end{abstract}

Keywords: wheat gluten; glycerol; bioplastics.

\section{INTRODUCTION}

The development of new materials to substitute synthetic polymers used in large scales is an important scientific and technological challenge. The use of proteins, lipids and polysaccharides has been extensively studied in order to obtain biopolymers, ${ }^{1,2}$ being a potentially interesting alternative to get also biodegradable films that can be used for food packaging, for instance. However, the necessary level of values demanded for the mechanical properties of the films, such as the tensile strength, the elasticity and the elongation at rupture, still constitutes a problem that remains as elusive as ever. Vegetable proteins such as those from wheat gluten, soybean and corn, and animal proteins such as those from egg, milk, keratin, collagen and gelatin have been the focus of studies to obtain bioplastics. ${ }^{1-8}$ Biopolymers derived from proteins show high degradation rates in the environment, which means that they are promising candidates to produce biodegradable materials with functional properties. ${ }^{5}$

Wheat gluten contains approximately $80 \%$ of protein constituted by two water-insoluble proteins: prolamin (gliadin), a monomeric protein, and glutenin (glutelin) an oligomeric protein, ${ }^{9,10}$ in an approximate 60/40 ratio, ${ }^{11}$ respectively. When moisturized, these proteins constitute a three-dimensional network with well-defined properties of viscoelasticity and cohesiveness. These properties for wheat proteins are different from those of other cereal and vegetable proteins, and the structure and property of glutens depend on the gliadin and glutenin interactions.

When wheat gluten is plastic-coated, a cohesive mixture with viscoelastic properties, that is a barrier to oxygen, is produced; ${ }^{3,12}$ and, due these characteristics, several authors have suggested that wheat gluten can be used as raw material to produce edible films, biodegradable films, or materials for biodegradable packaging. ${ }^{3}$ Though the extensive inter- and intrachain interactions of proteins caused by hydrogen bonds, electrostatic forces, hydrophobic interactions, and/or disulfide bonds or cross-linking, the resulting films are fragile, ${ }^{9}$ which restricts their applications in packaging. A common way to reduce the fragility of the polymeric material

*e-mail: shanaferreira@gmail.com is to add a plasticizer ${ }^{13}$ to it, which helps to avoid the breaking and the splinter of the films during the biopolymer manipulation and storage. ${ }^{14}$

The plasticizer is a hydrophilic liquid of low molecular weight and low volatility that reduces the chain to chain interaction of the protein ${ }^{13}$ and modifies the three-dimensional structure of the proteins. ${ }^{14}$ Glycerol and sorbitol are plasticizers that show a general behavior that follows the Couchmann-Karasz relationship to predict the $T_{g}$ of biopolymers as a function of their plasticization level. ${ }^{15}$ In the production of biodegradable packaging with a protein base, two methods can be used. ${ }^{3}$

1. A casting method or physicochemical process, which leads to film formation under low humidity conditions. This method uses a chemical reagent or a physical agent to break the intermolecular bonds, covalent or non-covalent, and stabilizes the polymer into native form, mainly the disulfide bond, resulting in protein dispersion and solubilization. Later, the movable polymer chains are organized and guided in the desired form, allowing the formation of new intermolecular bonds and interactions that stabilize a new three-dimensional network; finally, the product is dried. ${ }^{9}$

2. A mechanical method or thermoplastic process, which uses the thermoplastic properties of the proteins under low humidity conditions. The process starts by mixing the proteins and plasticizer to obtain a uniform mass. ${ }^{16,17}$ This method promotes a reversible change of proteins from rigid or glassy to flexible or elastic through a temperature increase and plasticizer addition.

The glass transition temperature $\left(\mathrm{T}_{\mathrm{g}}\right)$ of high-molecular weight polysaccharides and proteins (and mixtures of both) was studied by several researchers. ${ }^{18-21}$ Hoseney et al. ${ }^{22}$ were the first ones to demonstrate that the gluten wheat polymer is amorphous with glassy characteristics, and can be plastic-coated with water to lower the $T_{g}$.

Protein extrusion is a method commonly used to obtain plastic-coated polymeric materials; however, the properties of the extruded material depend on the processing conditions. ${ }^{23}$ The operational conditions of extrusion of the proteins limit the severity of the process ${ }^{10,23,24}$ and the machinery and steps used in plastics production can also be used in biopolymer extrusion, including thermoforming, injection or compression molding and extrusion. ${ }^{25}$ 
The objective of this study is to obtain biopolymers from mixtures of wheat gluten and glycerol by approximately isothermal and adiabatic processes and determine their rheological properties, with a long-term view to their use in packaging applications.

\section{EXPERIMENTAL}

\section{Materials}

The wheat gluten (WG) was acquired from RIBA S.A., Barcelona, Spain, containing $83 \%$ of proteins, 1.5 to $2 \%$ of lipids, $0.8 \%$ of ashes, and humidity inferior to $8 \%$ in weight. Before the processing, the gluten was dried in a greenhouse with air circulation at $75{ }^{\circ} \mathrm{C}$ for $8 \mathrm{~h}$.

The plasticizer used was glycerol (G) P.A. with $99.5 \%$ of purity (PANREAC), molar mass was $92.09 \mathrm{~g} \mathrm{~mol}^{-1}$, and relative density of 1.257 .

The bioplastic was obtained by two thermomechanical processes: isothermal $\left(80^{\circ} \mathrm{C}\right)$ and adiabatic at the Chemical Engineering Laboratories of the Chemical Engineering Department of the University of Huelva (Spain) using a torque rheometer with an adiabatic mixing chamber (Rheocord, Haake, Germany) provided with two counter-rotating cylinders ("roller" type), rotating with different angular speeds with a 3:2 ratio. Torque and temperature were registered during the mixture process.

The samples were batch-processed ( $250 \mathrm{~g}$ each batch) with a ratio of $0.40 \mathrm{~g}$ of glycerol per $1.00 \mathrm{~g}$ of wheat gluten $(0.40 \mathrm{G} /$ WG) that corresponds approximately to $80 \%$ of the total volume of the chamber $\left(310 \mathrm{~cm}^{3}\right)$; the mixing speed was set at a constant $50 \mathrm{rpm}$ and the mixing times were $180 \mathrm{~min}$ for the adiabatic process and $15 \mathrm{~min}$ for the $80{ }^{\circ} \mathrm{C}$ isothermal process. The other parameters were maintained according to the recommendations of other authors..$^{25,26}$

The resulting bioplastic was stored in polyethylene bags tightly closed and maintained at room temperature until its characterization.

\section{Methods}

The viscoelastic properties were determined in small-amplitude oscillatory shear using a rotational rheometer (TA Instruments AR G2) with a parallel-plate geometry of $25 \mathrm{~mm}$ diameter and a gap between 1 and $3 \mathrm{~mm}$. Initially, it was necessary to determine the area of linear viscoelastic response of the bioplastic by performing stress sweeps at a constant frequency of $0.6283 \mathrm{rad} \mathrm{s}^{-1}(0.1 \mathrm{~Hz})$ and $62.83 \mathrm{rad} \mathrm{s}^{-1}(10 \mathrm{~Hz})$. The frequency sweep tests were performed in a frequency range between 0.01 and $100 \mathrm{rad} \mathrm{s}^{-1}$ at $60{ }^{\circ} \mathrm{C}$ to determine the elasticity $\left(G^{\prime}\right)$ and loss moduli $(G$ ").

Thermal analysis of the bioplastics was performed by modulated differential scanning calorimetry (MDSC). Samples from 10 to $20 \mathrm{mg}$ of bioplastics were placed in aluminum capsules, hermetically sealed and taken to the differential Q100 calorimeter (TA Instruments, USA) using nitrogen as purge gas at a flow rate of $50 \mathrm{~mL} \mathrm{~min}{ }^{-1}$. A full temperature scan was performed between -50 and $200{ }^{\circ} \mathrm{C}$ at a heating rate of $5^{\circ} \mathrm{C} \mathrm{min}^{-1}$, modulation period of $60 \mathrm{~s}$ and amplitude modulation of $0.5^{\circ} \mathrm{C}$.

Samples of $10 \mathrm{mg}$ of the bioplastics were taken for TGA analysis using a thermogravimetric balance (TA Q500 - TA Instruments, USA) by varying the temperature from 30 to $400{ }^{\circ} \mathrm{C}$ at a heating rate of $10{ }^{\circ} \mathrm{C} \mathrm{min}^{-1}$ in a nitrogen atmosphere $\left(60 \mathrm{~mL} \mathrm{~min}{ }^{-1}\right)$. The temperatures at which there was loss of weight were determined directly from the thermograms.

\section{RESULTS AND DISCUSSION}

\section{Effects of mixing time in torque and temperature in the process thermoplastic}

The mixing time is an important factor in the change of torque and temperature in the mixing process (Figure 1). The torque shows three well defined regions: Initially there is an induction period, from the beginning until approximately $110 \mathrm{~min}$, in which the torque remains almost constant. A second region is well defined in the range between 110 and $122 \mathrm{~min}$ and in this the torque shows a sudden increase and reaches a maximum value of approximately $100 \mathrm{~N} \mathrm{~m}$. The third region starts at about $122 \mathrm{~min}$ and in this a sudden decrease of the torque occurs until a constant value of approximately $40 \mathrm{~N} \mathrm{~m}$ is obtained at $140 \mathrm{~min}$. This behavior is approximate to that reported by Jerez et al. ${ }^{27}$ for mixtures of $50 \%$ glycerol and wheat gluten, however, the three regions showed up at different times depending on the mixing speed, with the torque decreasing with increasing speed.

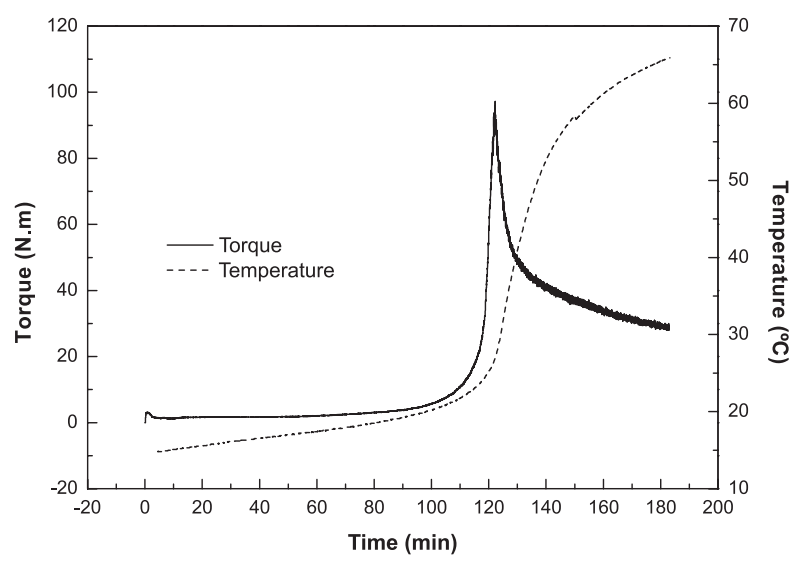

Figure 1. Evolution of the torque and temperature during the process of thermoplastic mixing of $0.40 \mathrm{G} / \mathrm{WG}$ in adiabatic conditions

The time required for the induction period decreases with increasing mixing speed in the initial region and the protein molecules are still entangled. The region of rapidly increasing torque is a consequence of the denaturation of the protein and increasing disorder degree in its structure. The final region of torque decrease features a further arrangement of the protein molecules, probably due to the effect of plasticizer.

The evolution of temperature in the mixing chamber showed three distinct steps: one between the beginning of the process up to approximately $120 \mathrm{~min}$ in which there was a small increase in temperature (around $25^{\circ} \mathrm{C}$ ); between 120 and $150 \mathrm{~min}$ there is an increase of 30 ${ }^{\circ} \mathrm{C}\left(1{ }^{\circ} \mathrm{C} \mathrm{min}^{-1}\right)$, after which the temperature gradually increases at approximately $0.7{ }^{\circ} \mathrm{C} \mathrm{min}{ }^{-1}$, reaching $70{ }^{\circ} \mathrm{C}$ after the full $180 \mathrm{~min}$. Mixtures of $50 \%$ glycerol showed near temperature changes. ${ }^{27}$

A total process time of $120 \mathrm{~min}$ was initially estimated for the preparation of bioplastic, but the resulting mass showed no cohesiveness or elasticity and was not suitable as bioplastic; however, after only 15 min a mass with good viscosity and elasticity levels was obtained.

In the isothermal process at $80^{\circ} \mathrm{C}$ (Figure 2) there was virtually no induction region, the torque rapidly reaching its maximum value of $50 \mathrm{~N} \mathrm{~m}$ after about $1 \mathrm{~min}$, immediately followed by a gradual decrease down to $30 \mathrm{~N} \mathrm{~m}$ after $5 \mathrm{~min}$ and remaining constant thereafter. Although the process was intended to be isothermal there was a gradual increase in temperature up to approximately $60^{\circ} \mathrm{C}$ after about $10 \mathrm{~min}$; after this, the process temperature remained virtually constant. This increase is probably the result of the frictional forces that are promoted in the process and result in viscous heating of the mass. 


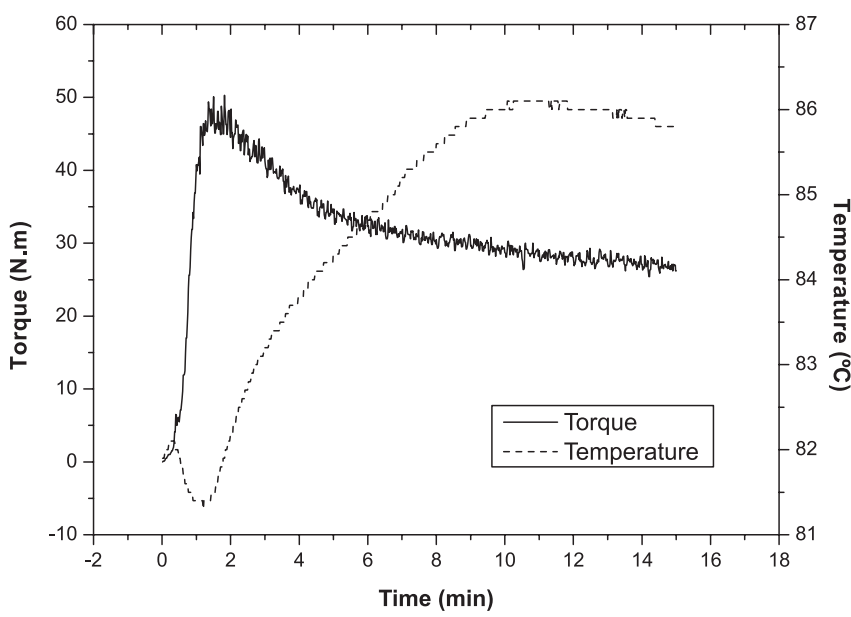

Figure 2. Torque and temperature evolution during blending of $0.40 \mathrm{G} / \mathrm{WG}$ under isothermal conditions

\section{Thermorheological behavior of bioplastic 0.40 G/WG}

The dynamic mechanical spectrum depicted in Figure 3 shows the effect of frequency on the storage $\left(G^{\prime}\right)$ and loss $(G$ ”) moduli of bioplastic $(0.40 \mathrm{G} / \mathrm{WG})$. Close to what was also reported by other authors ${ }^{10,27,28}$ for G/WG bioplastics, our results show that both processes lead to almost gel-like materials, with $G$ ' and $G$ " slowly increasing as a function of frequency, and the former much smaller than the latter. In particular, $\tan (\delta)$ increases from 0.15 to 0.5 in the adiabatic process and between 0.1 and 0.65 for the adiabatic process. For both processes the resulting materials are strongly shear-thinning, with power-law indices respectively of 0.19 and 0.18 .

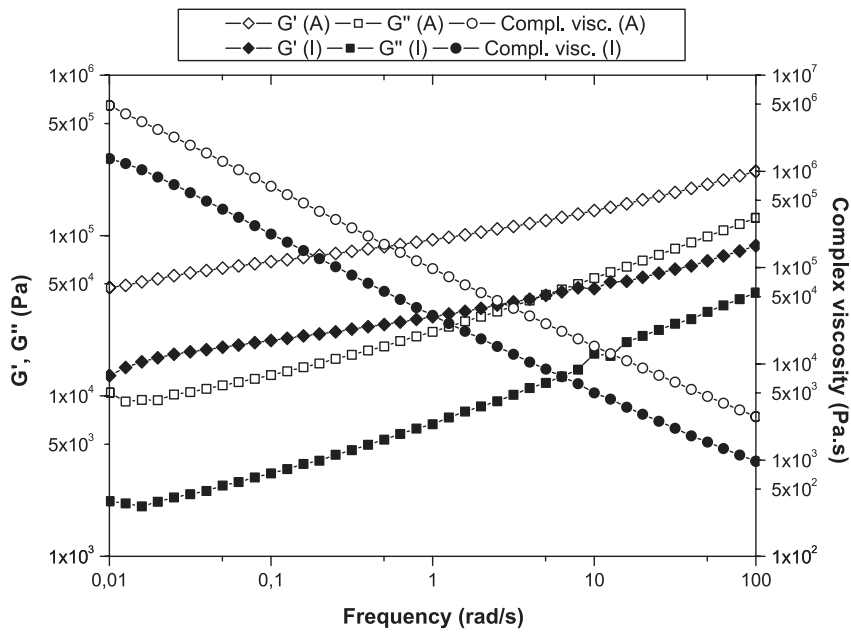

Figure 3. Dynamic mechanical spectra of glycerol bioplastics: wheat gluten $(0.40 \mathrm{G} / W G)$ bioplastics obtained by adiabatic (A) and isothermal (I) processes. Test temperature was $60^{\circ} \mathrm{C}$

Despite these similarities, the higher absolute values of $G$ ' and $G$ " moduli and the complex viscosity, $\eta^{*}$, for the adiabatic process suggest that the protein molecules form a stronger highly cross-linked and elastic network than in the isothermal process.

The cross-linked network is results by the amount of polar side groups in the primary structure, especially those with carbonyl groups, that is, glutamine, asparagine, glutamic acid, and aspartic acid. The presence of cysteine made the protein less sensitive to plasticization due to formation of a robust cystine cross-linked network. ${ }^{29,30}$ Other reports ${ }^{26,27}$ to $0.50 \mathrm{G} / \mathrm{WG}$ samples at different mixing times revealed changes in the microstructure of bioplastics and concluded that probably the mixing time induces significant changes in molecular microstructure, with glycerol/wheat gluten bioplastics after 10 min of mechanical mixing showing a spectrum typical of non-completely denatured protein molecules. However, after 45 min of mixing the dynamic mechanical spectrum showed a highly cross-linked protein network with values of high $G$ ' and $G$,", just like in the present work.

The total heat flow as a function of temperature (Figure 4), thermogram obtained by MDSC, revealed that both biofilms have near endothermic properties. The bioplastic from the isothermal process shows a lower peak temperature of $125^{\circ} \mathrm{C}$ than that from the adiabatic process, in which the peak appears at $140{ }^{\circ} \mathrm{C}$, indicating that the isothermal process promoted structural changes in the protein molecules at lower temperature than the adiabatic process. This result is in accordance to that reported by Jeréz et al.. ${ }^{26,27}$ They found the temperature of the endothermic peak between 150 and $160{ }^{\circ} \mathrm{C}$ for bioplastic from wheat gluten and glycerol obtained in adiabatic process. The temperature difference of bioplastics could be attributed to the different structure of proteins resulting from both processes that promoted the formation of different types forces that stabilize the polymer, such as disulfide bonding ${ }^{30}$ and polar side groups. ${ }^{29}$

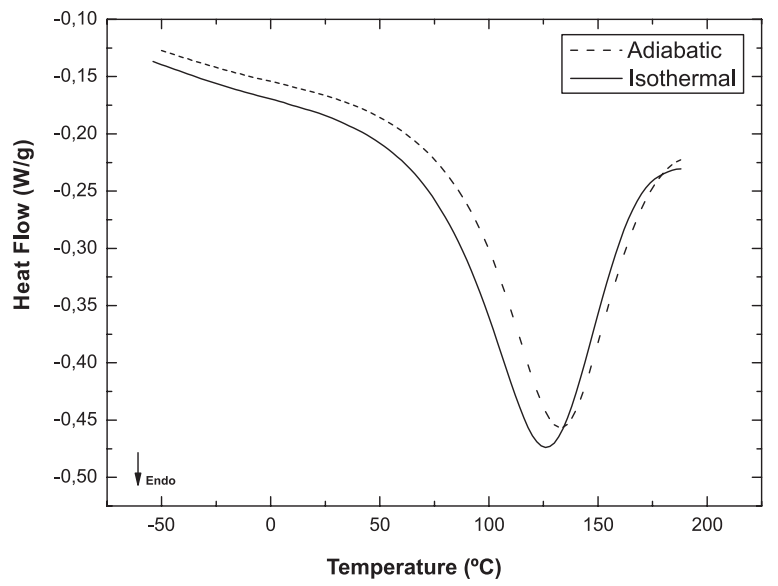

Figure 4. MDSC thermogram of bioplastics glycerol: wheat gluten $(0.40 \mathrm{G} /$ $W G)$ bioplastics obtained by adiabatic and isothermal processes

Both bioplastics showed the same thermogravimetric profile (Figure 5), probably due to that both polymers tend to degrade in a close manner as a function of temperature. However, it is possible to observe the existence of steps, labeled as steps A to $\mathrm{D}$ in the figure. Step A, which occurs below $180{ }^{\circ} \mathrm{C}$, corresponds to the elimination of both free and bound water, and, in this case, the weight loss is approximately $17 \%$. Step B, in which there is a further $29 \%$ weight loss, occurs between 180 and $280{ }^{\circ} \mathrm{C}$ and corresponds to the evaporation of glycerol. In step C, which occurs between 280 and $340{ }^{\circ} \mathrm{C}$, there is a further $26 \%$ weight loss; this step is associated with the breaking of covalent peptide bonds in amino acid residues. Finally, step D occurs above $340^{\circ} \mathrm{C}$ and corresponds to the breaking of disulfide bonds. ${ }^{31}$

The hygroscopic capacity of bioplastics from wheat gluten-glycerol mixture, expressed as weight loss as a function of temperature, has been reported by other authors ${ }^{25}$ with results approximate to those shown in Figure 5. The ability to retain water in the structure of the biopolymer is an interesting feature that may be desirable when the vehicle can be water or culture broth. 


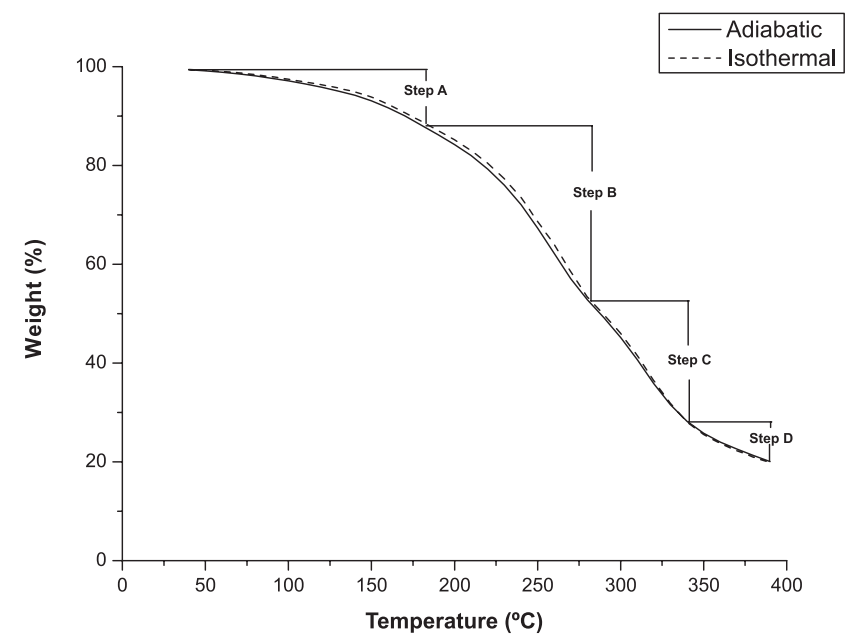

Figure 5. Thermogram of the effect of temperature on weight loss of the 0.40 G/WG bioplastics

\section{CONCLUSIONS}

Mixing of wheat gluten / glycerol under approximately adiabatic and isothermal conditions led to materials with final near rheological characteristics, indicating that close types of structure are obtained in both processes. In fact, our results showed that both processes lead to almost gel-like materials with values of $\tan (\delta)$ much lower than 1 . For both processes the resulting materials are strongly shear-thinning, with power-law indices respectively of 0.19 and 0.18 . However, biopolymers obtained by the adiabatic process have higher storage and loss moduli than those obtained in isothermal process, what indicates that the protein network formed in the former case is stronger (albeit of the same physicochemical type) than that in the latter.

MDSC and TGA analysis confirmed that both biopolymers have approximate structures albeit with different strengths: the thermogravimetry results are exactly the same for both biopolymers, and MDSC thermograms showed the endothermic peak at $125^{\circ} \mathrm{C}$ for the isothermal biopolymer, while that obtained in the adiabatic process only appears at $140{ }^{\circ} \mathrm{C}$.

Mixing time was an important factor in the torque and temperature evolution. Isothermal conditions $\left(80^{\circ} \mathrm{C}\right)$ favor lower mixing times, of the order of $15 \mathrm{~min}$, for obtaining the optimal rheological properties, whereas in the adiabatic case, although the final network is stronger, the processing times are much longer.

\section{ACKNOWLEDGEMENTS}

One of the authors (S. P. Ferreira) would like to acknowledge the support of Program Alban, Scholarship Program for high-level European Union to Latin America, scholarship No E06M104071BR, for partially funding this work.

\section{REFERENCES}

1. De Graaf, L. A.; J. Biotechnol. 2000, 79, 299.

2. Irissin-Mangata, J.; Bauduin, G.; Boutevin, B.; Gontard, N.; Eur. Polym. J. 2001, 37, 1533 .

3. Cuq, B.; Gontard, N.; Guilbert, S.; Cereal Chem. 1998, 75, 1.

4. Cuq, B.; Gontard, N.; Guilbert, S.; LWT-Food Sci. Technol. 1999, 32, 107.

5. Domenek, S.; Feuilloley, P.; Gratraud, J.; Morel, M.; Guilbert, S.; Chemosphere 2004, 54, 551.

6. Mine, Y.; Trends Food Sci. Technol. 1995, 6, 225.

7. Pommet, M.; Redl, A.; Morel, M.; Guilbert, S.; Polymer 2003, 44, 115.

8. Yamauchi, A.; Yamauchi, K. In Protein-based films and coatings; Gennadios, A., ed.; CRC Press: Boca Raton, 2002, chap. 10. Protein-Based Films and Coatings. Feb 2002 Parte inferior do formulário

9. Morel, M. H.; Micard, V.; Gontard, N.; Chalier, P.; Guilbert, S.; Redl, A. In ref. 8, chap. 3 .

10. Redl, A.; Morel, M.; Bonicel, J.; Guilbert, S.; Vergnes, B.; Rheol. Acta 1999, 38, 311 .

11. Shewry, P.; Tatham, A.; J. Cereal Sci. 1997, 25, 207.

12. Macritchie, F.; Advances in food and nutrition research 1992, 36, 1.

13. Mangavel, C.; Barbot, J.; Guéguen, J.; Popineau, Y.; J. Agric. Food Chem. 2003, 51, 1447.

14. Matveev, Y. I.; Grinberg, V. Y.; Tolstoguzov, V. B.; Food Hydrocolloids 2000, 14, 425 .

15. Pouplin, M.; Redl, A.; Gontard, N.; J. Agric. Food Chem. 1999, 47, 538.

16. Attenburrow, G. E.; Davies, A. P.; Goodband, R. M.; Ingman, S. J.; J. Cereal Sci. 1992, 16, 1.

17. Kokini, J. L.; Cocero, A. M.; Makeda, H.; De Graaf, E.; Trends Food Sci. Technol. 1994, 5, 281.

18. Kalichevsky, M. T.; Blanshard, J. M. V.; Carbohydr. Polym. 1992, 19, 271.

19. Kalichevsky, M. T.; Jaroszkiewicz, E. M.; Ablett, S.; Blanshard, J. M. V.; Lillford, P. J.; Carbohydr. Polym. 1992, 18, 77.

20. Lourdin, D.; Coignard, L.; Bizot, H.; Colonna, P.; Polymer 1997, 38, 5401.

21. Madeka, H.; Kokini, J.; Cereal Chem. 1996, 73, 433.

22. Hoseney, R.; Zeleznak, K.; Lai, C.; Cereal Chem 1986, 63, 285.

23. Redl, A.; Guilbert, S.; Morel M.; J. Cereal Sci. 2003, 38, 105.

24. Mitchell, J. R.; Areas, J. A.; Rasul, S.; Coloma, P.; Della Valle, G. In La caisson extrusion, Technique et documentation; Coloma, P.; Della Valle, G., eds.; Lavoiser: Paris, 1994.

25. Jeréz, A.; Partal, P.; Martinez, I.; Rheol. Acta 2007, 46, 711.

26. Jeréz, A.; Partal, P.; Martinez, I.; Gallegos, C.; Guerrero, A.; J. Food Eng. 2007, 82, 608.

27. Jeréz, A.; Partal, P.; Martinez, I.; Gallegos, C.; Guerrero, A.; Biochem. Eng. J. 2005, 26, 131.

28. Waldmann, A.; Branco, M.; Martins, A.; Abstracts the XI International Macromolecular Colloquim \& $6^{\text {th }}$ International Symposium on Natural Polymers and Composites, Gramado, Brazil, 2007.

29. Athamneh, A. I.; Griffin, M.; Whaley, M.; Barone, J. R.; Biomacromolecules 2008, 9, 3181.

30. Song, Y.; Zheng, Q.; Food Hydrocolloids 2008, 22, 674.

31. Sun, S.; Song, Y.; Zheng, Q.; Food Hydrocolloids 2007, 21, 1005. 